\title{
Saúde Mental e Saúde do Trabalhador: Análise das Conferências Nacionais Brasileiras
}

Mental health and worker's health: Analysis of the brazilian national conferences

Tatiana Ramminger Escola Nacional de Saúde Pública Sérgio Arouca Fundação Oswaldo Cruz

Henrique Caetano Nardi Universidade FederaL do Rio Grande do Sul 


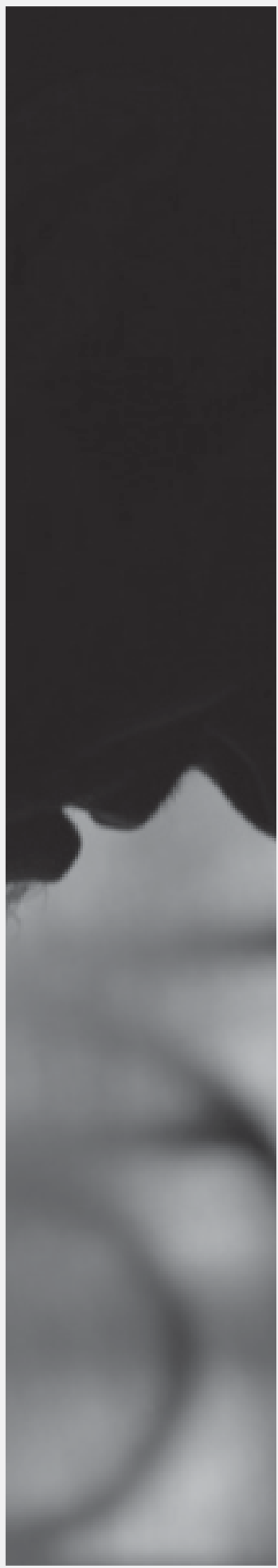

Resumo: No presente artigo, analisamos os principais documentos que sustentam as políticas de Saúde Mental e de Saúde doTrabalhador no Brasil, quais sejam, os relatórios das Conferências Nacionais, sublinhando como a Saúde Mental, enquanto tema, aparece no discurso da Saúde doTrabalhador e vice-versa: como a Saúde doTrabalhador é apresentada no discurso da Saúde Mental. Percebemos que a Saúde Mental, enquanto tema, é apresentada em ambas as Conferências Nacionais de Saúde do Trabalhador, embora com ênfases distintas e direcionadas à discussão do trabalho na iniciativa privada. Já a Saúde doTrabalhador, enquanto objeto das Conferências Nacionais de Saúde Mental, foi paulatinamente adquirindo importância e passou de uma reivindicação pela inclusão do tema da Saúde Mental do trabalhador na legislação e nas empresas até a uma preocupação específica com a Saúde Mental do trabalhador da saúde e com o servidor público. Concluímos que as conferências denotam o jogo técnico e político da construção de uma nova cidadania brasileira, a partir da disputa pela forma de institucionalização do SUS. Palavras-chave: Saúde Mental, Saúde do Trabalhador, políticas públicas, Conferências Nacionais de Saúde.

Abstract: In this article we analyze the main documents that give support to mental health and worker's health programs in Brazil, i.e., National Conferences' reports that give emphasis to the way mental health, as an issue, is present in the discourse of the worker's health's programs and vice versa, i.e., how the worker's health issues appear in the mental health programs' discourse. We found that mental health issues are present in both Worker's Health National Conferences, although with different emphasis and mainly related to the private companies' workers. On the other hand, worker's health, as a subject present in Mental Health National Conferences, gradually gained importance, going from a demand to include the theme of mental health in the labor regulation legislation of the private sector to a specific concern about the mental health of the public sector's worker. We conclude that the conferences show the political and technical struggle for the construction of a new Brazilian citizenship, originated in the dispute for the institutionalized form assumed by the Brazilian Health System (SUS).

Key words: Mental Health, Worker's Heath, public policies, National Health Conferences 
Não basta, portanto, investir em capacitação e formação dos trabalhadores dos novos serviços de Saúde Mental sem o concomitante compromisso de criar espaços de reflexão sobre o trabalho, para além da afirmação de verdadese respostas, nos quais se possa construir coletivamente um novo saber, considerando, sobretudo, as experiências dos trabalhadores.

1 Aqui nos referimos Saúde doTrabalhador enquanto rede enunciativa, pois temos ciência que, no Brasil, o trabalhador continua alijado do campo que discute a relação entre saúde e trabalho.

2 Expressão do antigo Código Civil Brasileiro, em vigor até 2002.
Em pesquisa que concluímos recentemente (Ramminger, 2006), um dos objetivos foi analisar as relações de força que perpassam os acontecimentos históricos e determinam os diferentes regimes de verdade (Foucault, 1999a) que sustentam as políticas públicas de saúde no Brasil, especialmente a Saúde Mental e a Saúde doTrabalhador. Isso se deve ao fato de que, ao escolher o amplo campo da reforma psiquiátrica como objeto de estudo, optamos por privilegiar os trabalhadores de Saúde Mental, considerando que outras formas de entendimento e cuidado em Saúde Mental só são possíveis a partir da mudança nos modos de trabalhar, ao se assumir uma postura crítica e política, modificar a organização do trabalho e viabilizar ações de atenção à Saúde doTrabalhador.

Basaglia (1991), idealizador da reforma psiquiátrica italiana que inspirou a reforma psiquiátrica brasileira, afirmava que a principal característica dos estabelecimentos psiquiátricos é uma separação entre aqueles que têm o poder e aqueles que não o têm. Foucault (1999b, p. 124), na mesma direção, afirmava que "todas as grandes reformas, não só da prática psiquiátrica mas também do pensamento psiquiátrico, se situam em torno dessa relação de poder, e são tentativas de deslocar a relação, mascará-la, eliminá-la, anulála”. Isso nos leva a pensar que talvez o que legitime um processo de desinstitucionalização seja a mudança efetiva na rede de relações de poder, o que inclui tanto a relação entre os trabalhadores como a destes com os gestores e com os usuários.

Palombini (2003, p. 161), pesquisadora brasileira, também enfatiza o quanto ainda temos que avançar nas relações de trabalho daqueles que se ocupam do cuidado dos loucos. Salienta que a ética que rege tais relações não se destaca daquela que, hegemonicamente, regulou a relação com a loucura nos hospitais psiquiátricos, pois a lógica manicomial se sustentou no tratamento moral e instituiu " a obediência como modo de relação, desautorizando a invenção $e$ prescrevendo comportamentos”. A autora conclui que uma subversão dessa lógica "somente se faz efetiva se é capaz de subverter também o modo hierarquizado, autoritário e prescritivo que, historicamente, moldou a constituição das equipes de trabalho no campo da Saúde Mental”.

Não basta, portanto, investir em capacitação e formação dos trabalhadores dos novos serviços de Saúde Mental sem o concomitante compromisso de criar espaços de reflexão sobre o trabalho, para além da afirmação de verdades e respostas, nos quais se possa construir coletivamente um novo saber, considerando, sobretudo, as experiências dos trabalhadores. Aliás, a valorização da experiência e do saber do trabalhador sobre seu próprio trabalho é o principal diferencial do campo designado como Saúde do Trabalhador ${ }^{1}$, em relação a outros modos de pensar o trabalhador, a saúde e o trabalho como, por exemplo, a Medicina do Trabalho e a Saúde Ocupacional (Nardi, 1999).

Nesse campo, muito se tem pesquisado sobre a transformação dos modos de produção, com a inclusão de novas tecnologias e métodos de gestão, e em saber como isso afeta a organização do trabalho, a saúde e a subjetividade dos trabalhadores. Entendemos que as práticas de atenção em Saúde Mental também passam por uma significativa transformação e convocam os profissionais a rever seu entendimento a respeito da loucura ao sair da idéia de “cura” para a de "cuidados”, da ideologia do "reparo" para a de "direitos" (Saraceno, 1999). Desconstrução de saberes e certezas e exigência de um novo trabalhador - que agora não mais trabalha sob a proteção dos muros dos hospitais, mas deve circular pela cidade, que não mais trabalha com "loucos de todo gênero" mas com “cidadãos”. Efetuase, dessa forma, a transição do hospital para a cidade: do conhecimento, da legislação, dos 
serviços, dos usuários, dos trabalhadores. Um interstício recheado por angústias, dúvidas, sofrimentos e resistências, mas também por possibilidades de criação e vida. Trata-se, portanto, de um espaço privilegiado para pautar a saúde no trabalho, que fomenta outros modos de fazer e de se relacionar com o trabalho em Saúde Mental.

É nesse sentido que consideramos importante incrementar o diálogo entre os campos da Saúde Mental e da Saúde doTrabalhador. Como forma de iniciar este debate, nossa contribuição, neste artigo, é analisar os principais documentos que sustentam as políticas de Saúde Mental e de Saúde doTrabalhador, quais sejam, os respectivos relatórios das Conferências Nacionais, sublinhando como a Saúde Mental, enquanto tema, aparece no discurso da Saúde doTrabalhador e vice-versa: como a Saúde doTrabalhador é apresentada no discurso da Saúde Mental.

A análise dos documentos foi guiada pela perspectiva genealógica de Foucault (1999c), que a entende como a possibilidade de constituir um saber histórico das lutas, da forma como a "verdade" é produzida em diferentes épocas, sendo que "por verdade, não quero dizer 'o conjunto das coisas verdadeiras a descobrir ou a fazer aceitar', mas o 'conjunto das regras segundo as quais se distingue o verdadeiro do falso e se atribui, ao verdadeiro, efeitos específicos de poder" (Foucault, 1999a, p.13). Sendo assim, o objetivo da pesquisa genealógica é analisar como se constroem as possibilidades de emergência dos discursos/ saberes (no caso aqui estudado, o da Saúde Mental e o da Saúde doTrabalhador) em determinados jogos de dominação e resistência que configuram a legitimidade da verdade para cada período.

\section{Saúde do Trabalhador na Saúde Mental}

Partimos agora para a análise de como se insere a questão da Saúde doTrabalhador ou, de modo mais amplo, a discussão do trabalho em Saúde Mental, nos principais documentos que sustentam a reforma psiquiátrica no Brasil, ou seja, nos relatórios das Conferências Nacionais de Saúde Mental.

A I Conferência Nacional de Saúde Mental, realizada em 1987, no Rio de Janeiro, acontece logo após a VIII Conferência Nacional de Saúde (em Brasília, 1986), e o Encontro Nacional dos Trabalhadores da Saúde Mental (em Bauru, 1987). Se a primeira apontava a efetivação de um Sistema Único de Saúde, o segundo desdobrou-se na criação do Movimento Nacional da Luta Antimanicomial, que reivindicava "uma sociedade sem manicômios”. A organização do Movimento determinou a agenda dessa I Conferência, que apresentou, como temas básicos: Economia, sociedade e Estado: impactos sobre saúde e doença mental; Reforma sanitária $e$ reorganização da assistência à Saúde Mental, e Cidadania e doença mental: direitos, deveres e legislação do doente mental. Nesse momento, parece mais importante marcar o impasse frente ao modelo centrado no hospital psiquiátrico e sustentar a condição cidadã dos usuários. Só assim seria possível começar a discutir, de forma mais aprofundada, a reorganização da assistência e as mudanças no trabalho em Saúde Mental (BRASIL, 1987). A II Conferência Nacional de Saúde Mental, realizada em dezembro de 1992, já acontece após a implantação do SUS - Sistema Único de Saúde, e torna-se a inspiração de toda a legislação posterior em relação à reversão do modelo de atenção em Saúde Mental. Os grandes temas sobre os quais se centram as deliberações dos delegados e participantes são: Rede de atenção em Saúde Mental; Transformação e cumprimento de leis; Direito à atenção e Direito à cidadania (BRASIL, 1993). Na primeira parte do Relatório, encontramos os marcos conceituais da Conferência. Na segunda parte, temos as deliberações, divididas nos seguintes capítulos: Recomendações gerais; Financiamento; "por verdade, não quero dizer 'o conjunto das coisas verdadeiras a descobrir ou a fazer aceitar', mas o 'conjunto das regras segundo as quais se distingue o verdadeiro do falso e se atribui, ao verdadeiro efeitos específicos de poder"

Foucault 
Gerenciamento; Vigilância; Dos trabalhadores de saúde; Da organização do trabalho e da pesquisa. A terceira e última parte aborda os direitos e a legislação, compondo-se dos capítulos Questões gerais sobre a revisão legal necessária; Direitos civis e cidadania; Direitos trabalhistas; Drogas e legislação e Direitos dos usuários.

O capítulo que versa sobre o trabalho e o trabalhador de saúde enfatiza a necessidade de priorizar as ações que estimulem a "desinstitucionalização do trabalhador de Saúde Mental" bem como define a equipe de saúde como necessariamente multiprofissional, inclusive com trabalhadores das áreas artística, cultural e educacional, livre da tradicional divisão de funções, com uma participação mais efetiva dos auxiliares e atendentes, com respeito e escuta dos diferentes saberes, sobretudo dos "setores populares", e implicada no processo de mudança cultural do entendimento da saúde/doença mental. Aponta a necessidade de garantir práticas de ensino, pesquisa e extensão que "favoreçam novas atitudes dos futuros profissionais em relação à doença mental e que estimulem $o$ desenvolvimento do potencial dos indivíduos com sofrimento psíquico". Nesse capítulo, verifica-se o incentivo à criação de grupos de reflexão e supervisão, para que os profissionais de Saúde Mental possam repensar suas práticas; reivindica também a mudança na lógica das universidades formadoras de trabalhadores de saúde, que devem introduzir temas de Saúde Mental e saúde coletiva em seus currículos bem como a regulamentação do art. 200, inciso III, da Constituição Federal, que atribui ao SUS a tarefa de ordenação da formação dos trabalhadores de saúde.

Em relação à organização do trabalho, a Conferência aponta a garantia, dentro da carga horária contratual, de espaço para a "atualização, intercâmbio, pesquisa, supervisão de equipe e contato dos profissionais com as suas entidades, no sentido de romper a alienação e burocratização do trabalho". Sublinha que é necessário avançar no processo de organização do trabalho, sugerindo que as associações populares e profissionais lutem, juntas, por condições e organização de trabalho adequadas e coerentes com as mudanças em curso, "direcionadas à construção da cidadania dos pacientes e dos profissionais".

No entanto, é em seu Capítulo 10 - Dos direitos trabalhistas - que o Relatório evidencia, de forma mais contundente, a intersecção entre essas duas redes enunciativas das quais temos nos ocupado. A Saúde Mental soma-se à luta do campo da Saúde doTrabalhador, visando a assegurar, em um primeiro momento, o direito ao trabalho das pessoas portadoras de sofrimento psíquico. Posteriormente, lista várias recomendações que devem ser incluídas tanto na Consolidação das Leis do Trabalho - CLT como nos Estatutos dos funcionários públicos, tais como a diminuição do tempo de exposição dos trabalhadores às condições de fadiga e tensão psíquica, os períodos de descanso durante a jornada cotidiana destinados à preservação da atividade mental autônoma, a diversificação das atividades reconhecidamente desgastantes do ponto de vista psíquico e a formação de grupos de avaliação dos condicionantes de fadiga e de tensão psíquica. Sugere, ainda, a criação de centros de referência em Saúde doTrabalhador com equipes de Saúde Mental, a criação, no nível ministerial, de uma área destinada à Saúde Mental do trabalhador, o reconhecimento das doenças mentais como doença profissional sempre que haja nexo causal e a responsabilização das empresas que tenham causado algum mal psíquico aos seus funcionários. Ressaltamos que as recomendações se direcionam aos trabalhadores de forma ampla, sem referência explícita ao servidor público ou ao trabalhador dos serviços de saúde, o que reflete, nesse primeiro momento, a falta de uma problematização direta do trabalho em Saúde Mental. 
A III Conferência Nacional de Saúde Mental, realizada em 2001, Cuidar, sim. Excluir, não. Efetivando a Reforma Psiquiátrica com Acesso, Qualidade, Humanização e Controle Social, agrega, em seu título, o tema mundial proposto pela Organização Mundial da Saúde no mesmo ano (Cuidar, sim, excluir, não) e as discussões da $11^{\text {a }}$ Conferência Nacional de Saúde (Efetivando o SUS: acesso, qualidade e humanização da saúde, com controle social), realizada em 2000. O Relatório está dividido em seis capítulos: Reorientação do modelo assistencial em Saúde Mental; Recursos humanos; Financiamento; Acessibilidade; Direitos e cidadania e Controle social (Brasil, 2001). O contexto é o da recente aprovação da nova Lei Federal de Saúde Mental, em abril de 2001.

O Capítulo II que versa sobre os Recursos humanos, em que pese esse questionável título, prioriza a discussão da (re)organização do trabalho em Saúde Mental, mas também inclui a preocupação com a relação entre saúde e trabalho. Esse capítulo inicia dizendo que a consolidação dos princípios da reforma psiquiátrica requer uma política adequada de recursos humanos, integrada nos três planos: municipal, estadual e federal, e que "valorize e considere a importância do trabalhador de Saúde Mental na produção dos atos de cuidar, possibilitando o exercício ético da profissão”. Tal política deve contemplar: capacitação e qualificação continuadas, remuneração justa dos profissionais, planos de cargo, carreira e salários, democratização das relações e das discussões em todos os níveis de gestão, visando à transformação dos processos de trabalho com a superação das formas verticalizadas de gestão, incorporação das questões de segurança, saúde e Saúde Mental do trabalhador, supervisão clínica e institucional, avaliação de desempenho (não são elencados os parâmetros para tal avaliação) e jornada de trabalho adequada para todos os profissionais de nível superior bem como isonomia salarial entre eles (os profissionais de nível médio não são citados). As contratações devem ser feitas exclusivamente através de concursos públicos, salvo em situações de emergência, nas quais poderão ocorrer outras formas de contratação, mas assegurando-se sempre a seleção pública.

O Relatório reafirma a importância do trabalho interdisciplinar e multiprofissional, " $n a$ perspectiva do rompimento dos 'especialismos' e da construção de um novo trabalhador em Saúde Mental, atento e sensível aos diversos aspectos do cuidado" e aponta, ainda, a valorização da experiência de familiares e usuários na superação do "manicômio mental”, implícito no saber científico convencional que discrimina o saber popular. Mais adiante, traça o perfil do trabalhador em Saúde Mental e privilegia a "existência de uma dimensão subjetiva, humanizante, solidária e fraterna" que, no entanto, não deve significar "nenhuma disposição de aceitar condições de trabalho indignas e precárias ou aviltamento em sua remuneração”.

Percebemos uma grande ênfase e preocupação em relação à formação em Saúde Mental, com estratégias que vão desde a capacitação para a rede básica de saúde (médicos generalistas/ ESF/PACS), passando pela inclusão da Saúde Mental nos currículos universitários, até a capacitação dos profissionais de Saúde Mental em temas específicos, sobretudo o atendimento de crianças, adolescentes e usuários de drogas. O último tópico abordado (item 5), que se refere aos recursos humanos, é a "Saúde Mental do trabalhador" que, pelo nosso interesse particular, passamos a descrever na íntegra: "valorize e considere a importância do trabalhador de Saúde Mental na produção dos atos de cuidar, possibilitando o exercício ético da profissão". 


\section{“5.Saúde Mental do Trabalhador}

266.Desenvolver estratégias específicas para acompanhar e tratar da Saúde Mental dos trabalhadores da saúde.

267.Criar programas de Saúde Mental no âmbito da administração municipal para os funcionários e servidores portadores de sofrimento psíquico e/ou dependência de álcool e drogas.

268. Regulamentar o pagamento do adicional de insalubridade para os profissionais da saúde, conforme a legislação vigente.”

Por ocasião da Conferência, além desse Relatório, o Ministério da Saúde lançou um Caderno de Textos, no qual sinaliza que os temas centrais da reforma são: a reorientação do modelo assistencial, o financiamento e, novamente, os “recursos humanos". No mesmo Caderno, Vasconcelos (2001) discute a importância do controle social para a efetivação da reorientação do modelo assistencial em Saúde Mental no Brasil, salientando que é fundamental “ $a$ participação efetiva dos trabalhadores na garantia de boas condições de trabalho e na gestão democrática, pluralista e interdisciplinar dos serviços e programas de Saúde Mental, de forma integrada com os usuários $e$ familiares”. O artigo segue destacando o fato de a montagem de serviços efetivamente não manicomiais ser extremamente sensível ao processo de trabalho, que, quando consegue contemplar uma gestão democrática, com condições adequadas de trabalho e salário, garante um real compromisso dos trabalhadores com a clientela e os serviços. Só assim é possível "reinventar a formação teórico-metodológica e as identidades profissionais convencionais, requisitos necessários para a recriação de novas modalidades de cuidado em Saúde Mental”. Para tanto, são necessários dispositivos de formação e gestão participativa nos serviços que incluam reuniões interdisciplinares e regulares de equipes, grupos abertos de estudo e trabalho, assembléias, centros de estudos, seminários e cursos de educação continuada. O autor enfatiza, particularmente, as supervisões como espaços privilegiados de elaboração das dificuldades e conflitos, desde que não restritas apenas aos temas administrativos e clínicos, como geralmente acontece nos serviços de Saúde Mental. Para ele, as supervisões devem ser estruturadas de forma a incluir também a discussão das relações de poder, das dificuldades de trabalho em equipe, das inseguranças que todos os profissionais têm quando lidam com desafios que escapam à competência adquirida na formação universitária ou técnica convencional, das crises de identidade profissional, das dificuldades subjetivas da relação com a clientela, dos sintomas de estresse e síndrome de esgotamento (“burn out”), etc.

Concluindo, percebemos que o cruzamento do discurso da Saúde Mental e da Saúde doTrabalhador aparece, a partir da II Conferência Nacional de Saúde Mental, primeiro tentando garantir a discussão da Saúde Mental na Saúde doTrabalhador e, somente na III Conferência Nacional de Saúde Mental, pautando efetivamente a discussão da Saúde doTrabalhador, especialmente do trabalhador da saúde, na Saúde Mental.

A seguir, apresentamos um quadro resumido com o contexto, os eixos principais e as discussões das Conferências Nacionais de Saúde Mental em relação à Saúde doTrabalhador. 
Quadro 1 - Saúde do trabalhador nas Conferências Nacionais de Saúde Mental

\begin{tabular}{|c|c|}
\hline $\begin{array}{l}\text { conferência/ } \\
\text { ano }\end{array}$ & $\begin{array}{l}\text { contexto e } \\
\text { participantes }\end{array}$ \\
\hline $\begin{array}{r}\text { I Conferência } \\
\text { Nacional De } \\
\text { Saúde Mental } \\
-1987\end{array}$ & $\begin{array}{l}\text { - VIII Conferência } \\
\text { Nacional de Saúde;- } \\
\text { Encontro Nacional } \\
\text { dos Trabalhadores de } \\
\text { Saúde Mental; } \\
\text { - Criação do } \\
\text { Movimento Nacional } \\
\text { da Luta } \\
\text { Antimanicomial }\end{array}$ \\
\hline
\end{tabular}

II

Conferência

Nacional De

Saúde Mental

- 1992

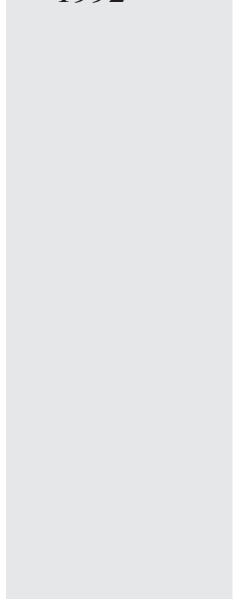

III

Conferência

Nacional

De Saúde

Mental -

2001

Constituição Federal de 1988;

Implantação do SUS

(Lei ${ }^{\circ}{ }^{8080 / 90)}$

500 delegados

Aprovação da

Lei Nacional

$\mathrm{n}^{\circ} 10.201 / 01$

1700 delegados eixos principais

1. Economia, sociedade e

Estado: impactos sobre

saúde e doença mental;

2. Reforma sanitária e

reorganização da

assistência à Saúde

Mental;

3. Cidadania e doença

mental: direitos, deveres

e legislação do doente

mental.
1. Rede de atenção em

Saúde Mental:

financiamento, gerenciamento, vigilância;

2. Trabalhadores de saúde, organização do trabalho e pesquisa;

3. Direitos e legislação: revisão legal necessária, direitos civis e cidadania, direitos trabalhistas, drogas e legislação, direitos dos usuários.

1. Reorientação do modelo assistencial em Saúde Mental;

2. Recursos humanos;

3. Financiamento;

4. Acessibilidade;

5. Direitos e cidadania;

6. Controle social. saúdedo trabalhador

Não é

mencionada.
Prioriza a organização do trabalho como dispositivo para a desinstitucionalização do trabalhador de Saúde Mental e define a equipe de saúde como multiprofissional, com espaço para "atualização, intercâmbio, pesquisa, supervisão de equipe e contato dos profissionais com as suas entidades, no sentido de romper a alienação e a burocratização do trabalho". Soma-se à luta do campo da Saúde doTrabalhador, visando a assegurar a inclusão do tema da Saúde Mental do trabalhador no nível central de governo, na legislação e nos serviços de saúde.

Defende uma política de recursos humanos para a Saúde Mental, que deve contemplar a capacitação e a qualificação continuadas, com supervisão clínica e institucional, remuneração justa; superação das formas verticalizadas de gestão, incorporação das questões de segurança, saúde e Saúde Mental do trabalhador. Preocupação específica com a Saúde Mental do trabalhador da saúde. 


\section{Saúde Mental na Saúde doTrabalhador}

Passemos agora a analisar como a temática da Saúde Mental foi tratada pelas Conferências Nacionais de Saúde do Trabalhador que já tiveram seus relatórios publicados. A I Conferência Nacional de Saúde do Trabalhador, realizada em dezembro de 1986, teve, como principal marca, a formulação de conteúdos para a Política Nacional de Saúde do Trabalhador, que foram incorporados na Constituição Federal de 1988 e na Lei ${ }^{\circ}$ 8080 , de 1990. Já na sua forma de organização, fica evidente o esforço para quebrar a hegemonia do Ministério do Trabalho, nitidamente ligado aos interesses empresariais, na discussão da Saúde doTrabalhador e levá-la efetivamente para o campo da saúde. Na falta de uma definição mais clara do Ministério da Saúde, quem coordena a organização da Conferência é o Centro de Estudos da Saúde do Trabalhador e Ecologia Humana, da Escola Nacional de Saúde Pública - Fiocruz. Os empresários foram os principais ausentes nos processos de discussão e deliberação, com apenas $1 \%$ de representação entre os delegados participantes.

Em seu relatório final (BRASIL, 1986), a Conferência estabelece o consenso de que a saúde dos trabalhadores extrapola os limites da saúde ocupacional e introduz o conceito ampliado de saúde, afirma a necessidade de se revisar a legislação e ampliar as listas de doenças ocupacionais, com uma legislação única que assegure os mesmos direitos a todos, independentemente de trabalharem na área urbana, rural, pública ou privada, e enfatiza, em vários momentos, a necessidade da criação de um Sistema Único de Saúde, com descredenciamento da rede privada e a criação de programas específicos de atendimento ao trabalhador. Tal sistema deve contar, ainda, com uma política de recursos humanos que reoriente a formação e a utilização dos trabalhadores da área de saúde pública, com remuneração digna dos mesmos. Em relação à fiscalização, o relatório sugere que as ações sejam responsabilidade do SUS, com participação dos trabalhadores, evitandose que os profissionais que realizam a fiscalização tenham vínculos com a empresa. Da mesma forma, criticam a subordinação dos SESMTs (Serviços de Engenharia, Segurança e Medicina do Trabalho) à classe patronal, e sugere que os mesmos fiquem sob o controle dos sindicatos ou das associações de classe. As questões relativas ao trabalho rural e à proibição do trabalho "do menor" são destacadas em vários itens. O relatório levanta a necessidade do envolvimento cada vez maior dos sindicatos na questão da saúde como objetivo de luta e ressalta a importância da organização dos trabalhadores para a abertura de novos espaços. Em seu último eixo, Política Nacional de Saúde dos Trabalhadores, estabelece os direitos básicos de Saúde doTrabalhador. Em relação aos portadores de deficiência, estabelece o direito ao trabalho, o acompanhamento em saúde, a reabilitação e a reinserção no trabalho bem como a aposentadoria especial.

A II Conferência Nacional de Saúde do Trabalhador foi realizada oito anos depois, sob a égide da Constituição Federal e da Lei Orgânica da Saúde, na qual está incorporada a atenção à saúde dos trabalhadores como papel do SUS. Seu tema central foi Construindo uma Política de Saúde do Trabalhador, e os temas complementares: Desenvolvimento, meio ambiente e saúde; Cenário de Saúde doTrabalhador de 1986 a 1993 e perspectivas e Estratégias de avanço na construção da Política Nacional de Saúde do Trabalhador. As principais marcas dessa conferência, segundo 
seu relatório, foram a definição da unificação das ações de Saúde doTrabalhador no SUS e a discussão das dimensões políticas, sociais, econômicas, técnicas e gerenciais dessa política pública. Compuseram o evento quatro mesas redondas e oito painéis específicos, entre eles, um sobre Saúde Mental (BRASIL, 1994).

O painel específico sobre Saúde Mental foi coordenado por Leny Sato, que representou o DIESAT - Departamento Intersindical de Estudos e Pesquisas de Saúde e dos Ambientes de Trabalho. Em suas considerações iniciais, Sato avalia que já existe, há várias décadas, o reconhecimento internacional de que determinadas formas de organização do trabalho, produtos químicos e novas tecnologias são nocivas à Saúde Mental. No entanto, foi apenas na década de 1980 que os pesquisadores brasileiros da área de Saúde Mental puderam inserir suas contribuições no campo da Saúde doTrabalhador e ampliar as ações tanto dos serviços públicos como dos sindicatos. Nessa época, por exemplo, foram realizadas as primeiras pesquisas pelo DIESAT, a partir de demandas sindicais, com os trabalhadores bancários (1985) e metroviários (1986), visando a conhecer os efeitos à Saúde Mental provocados pelas condições de trabalho, especialmente o trabalho automatizado. Embora ressalte que a discussão "Saúde Mental e trabalho" não se configura como tema prioritário para várias categorias de trabalhadores, avalia que, após oito anos da realização da I Conferência, um maior número de sindicatos de trabalhadores atuam em defesa da saúde dos trabalhadores. Para ela, essa luta implica detectar as condições de trabalho geradoras de agravos à saúde, aprofundar o conhecimento técnico desses agravos, o que inclui o conhecimento dos trabalhadores, e delinear estratégias de ação. Sendo assim, "uma das principais fontes de dados sobre a relação saúde e trabalho é aquela fornecida pela subjetividade, pelo conhecimento prático que os trabalhadores têm sobre essa relação".

Na fala de Pérsio Dutra, também pelo DIESAT, é reforçado o entendimento de que a Saúde Mental do trabalhador não é uma preocupação generalizada do movimento sindical, e o palestrante destaca que, em geral, os problemas de sofrimento mental chegam aos sindicatos travestidos sob a forma de manifestações orgânicas ou como problemas funcionais com a chefia e com a organização do trabalho em geral, ou ainda, como atritos nas relações interpessoais fora do trabalho. Ele retoma as duas pesquisas citadas por Sato e ressalta que tanto os bancários como os metroviários tiveram uma grande coincidência no perfil de sofrimento mental, de acordo com o ritmo e o objetivo do serviço e a introdução de tecnologias de controle (automação), e conclui que uma questão emergente e fundamental é o controle do processo produtivo, do seu objetivo e da tecnologia aplicada a ele. Com isso, afirma a necessidade do reconhecimento do nexo da causalidade entre o trabalho e sua organização no aparecimento dos agravos mentais, e minimiza a prática recorrente de localizar o problema mental nas características individuais de cada um ao negar sua relação com as condições de trabalho e de vida. Reflete sobre a dificuldade que enfrenta o trabalhador com sofrimento mental ao procurar tratamento e reconhecimento do nexo com o trabalho, isso porque, para ele, os médicos das empresas nunca irão estabelecer tal nexo, o sindicato está despreparado para defendê-lo, os profissionais da rede pública também têm dificuldade em associar seu quadro e, quando este é reconhecido e o trabalhador é enviado ao INSS - Instituto Nacional do Seguro Social, encontrará alguém que dirá que seu problema 
é individual e nada tem a ver com a organização e as condições de seu trabalho.

Uma das principais propostas aprovadas na plenária final foi a necessidade de unificação de todas as ações de Saúde doTrabalhador no Sistema Único de Saúde. Em relação à saúde do servidor público, aparece a preocupação em garantir ações dentro do sistema de vigilância e fiscalização nas instituições públicas e privadas (p.17), a criação de comissões de Saúde doTrabalhador nos serviços públicos e privados (p.20) e a exigência de que o serviço público, em todas as esferas de governo, enquanto empregador, passe a emitir CAT - Comunicação de Acidente de Trabalho (p.35).

Ao trabalhador da saúde, foi dedicado um capítulo específico (V - Recursos Humanos para a Saúde do Trabalhador), que afirma a necessidade de regulamentar e cumprir as regulamentações e resoluções já existentes em relação à formação de recursos humanos para a saúde, defende a idéia de que os Centros de Referência em Saúde doTrabalhador sejam locais de formação na área de saúde e trabalho e reconhece a natureza multidisciplinar e continuada da formação nessa área, bem como a necessidade de inclusão dos profissionais de serviço social e psicologia nas equipes de saúde, "permitindo maior humanização do serviço e defesa dos interesses dos trabalhadores". Na gestão dos recursos humanos pelo Estado, o governo deve investir na qualificação dos trabalhadores dos serviços públicos de saúde, ampliar, mediante concurso público, o quadro de pessoal voltado para as ações de Saúde doTrabalhador no SUS, implantar o Plano de Carreira, Cargos e Salários (PCCS), o que incentivará o regime de dedicação exclusiva para os profissionais da saúde, e regulamentar a formação profissional e a situação trabalhista dos agentes comunitários de saúde. Considerando a atuação dos profissionais da área, o relatório explicita que se deve “tomar como objeto de análise, nas ações de vigilância em Saúde doTrabalhador, as relações profissionais e institucionais a que estão submetidos os profissionais de saúde, contemplando, inclusive, aspectos de sua Saúde Mental” (p.27). Além desse ponto, o relatório apresenta outros itens específicos sobre a Saúde Mental, como a necessidade da contemplação de aspectos de Saúde Mental no reconhecimento de doenças profissionais (p.33) e a sugestão de que as empresas públicas e privadas mantenham programas educativos em relação ao alcoolismo (p.45).

Concluindo (vide quadro 2), percebemos que o cruzamento do discurso da Saúde doTrabalhador e da Saúde Mental aparece de forma incipiente na I Conferência Nacional de Saúde do Trabalhador, fortalecendo-se a partir da II Conferência Nacional de Saúde do Trabalhador, sobretudo pela influência de profissionais ligados às universidades. Pela própria avaliação realizada durante a Conferência, podemos perceber o quanto os técnicos ligados às universidades tiveram um papel importante e apontaram a dificuldade dos sindicalistas em eleger a questão do sofrimento psíquico como uma questão central. Salientamos que o relatório da III Conferência Nacional de Saúde do Trabalhador, mesmo que realizada há mais de um ano (dezembro de 2005), não pôde ser incluído nesta análise por não ter sido publicado até a redação final deste artigo (janeiro, 2007). 
Quadro 2 - Saúde mental nas Conferências Nacionais de Saúde do Trabalhador

\begin{tabular}{|c|c|c|c|}
\hline $\begin{array}{l}\text { conferência/ } \\
\text { ano/contexto }\end{array}$ & contexto e participantes & eixos principais & Saúde Mental \\
\hline $\begin{array}{l}\text { I Conferência } \\
\text { Nacional De } \\
\text { Saúde Do } \\
\text { Trabalhador } \\
\text { Dezembro } \\
1986\end{array}$ & $\begin{array}{l}\text { Realização da VIII } \\
\text { Conferência Nacional } \\
\text { de Saúde (março } \\
\text { 1986) } \\
399 \text { delegados, sendo } \\
46 \% \text { representantes de } \\
\text { trabalhadores, } 40 \% \text { do } \\
\text { Estado, 9\% das } \\
\text { universidades e 5\% de } \\
\text { outras categorias. }\end{array}$ & $\begin{array}{l}\text { 1. Diagnóstico da } \\
\text { situação de saúde e } \\
\text { segurança dos } \\
\text { trabalhadores; } \\
\text { 2.Novas alternativas de } \\
\text { atenção à saúde dos } \\
\text { trabalhadores; } \\
\text { 3. Política Nacional de } \\
\text { Saúde e Segurança dos } \\
\text { Trabalhadores. }\end{array}$ & $\begin{array}{l}\text { Em sua última temática, aparece uma } \\
\text { clara preocupação com o portador de } \\
\text { deficiência, que deve ter acesso ao } \\
\text { trabalho, acompanhamento médico, } \\
\text { psicológico e social, e aposentadoria } \\
\text { especial com } 25 \text { anos de trabalho. } \\
\text { Sugere, ainda, a substituição do } \\
\text { atestado de sanidade física e mental } \\
\text { por atestado de aptidão para a função. }\end{array}$ \\
\hline $\begin{array}{l}\text { II } \\
\text { Conferência } \\
\text { Nacional } \\
\text { De Saúde } \\
\text { Do } \\
\text { Trabalhador } \\
1994\end{array}$ & $\begin{array}{l}\text { Constituição Federal de } \\
1988 \text { e Lei Orgânica da } \\
\text { Saúde, de } 1990 . \\
\text { IX Conferência } \\
\text { Nacional de Saúde, de } \\
1992 . \\
560 \text { delegados, dos } \\
\text { quais 65,7\% } \\
\text { representantes dos } \\
\text { trabalhadores, 31,1\%, } \\
\text { do Estado, e 3,2\%, dos } \\
\text { empregadores. }\end{array}$ & $\begin{array}{l}\text { Tema central: } \\
\text { Construindo uma } \\
\text { política de Saúde } \\
\text { doTrabalhador. Temas } \\
\text { complementares: } \\
\text { 1. Desenvolvimento, } \\
\text { meio ambiente e } \\
\text { saúde; } \\
\text { 2. Cenário da Saúde } \\
\text { doTrabalhador de } 1986 \\
\text { a } 1993 \text { e perspectivas; } \\
\text { 3. Estratégias de avanço } \\
\text { na construção da } \\
\text { Política Nacional de } \\
\text { Saúde do Trabalhador. }\end{array}$ & $\begin{array}{l}\text { Um dos painéis específicos foi sobre } \\
\text { Saúde Mental e trabalho, onde se fez } \\
\text { uma avaliação da relação entre Saúde } \\
\text { Mental e trabalho no Brasil. No relatório } \\
\text { final, foi apontada a necessidade de se } \\
\text { contemplarem aspectos de Saúde } \\
\text { Mental no reconhecimento das doenças } \\
\text { profissionais, a inclusão dos profissionais } \\
\text { de serviço social e psicologia nas } \\
\text { equipes de Saúde doTrabalhador, e } \\
\text { ainda, que na vigilância em Saúde } \\
\text { doTrabalhador, sejam consideradas as } \\
\text { relações profissionais e institucionais a } \\
\text { que estão submetidos os profissionais } \\
\text { de saúde, inclusive os de Saúde } \\
\text { Mental. }\end{array}$ \\
\hline
\end{tabular}

Fonte: Relatórios da I e II Conferências Nacionais de Saúde do Trabalhador.

\section{À guisa de conclusão}

Tanto o campo da Saúde doTrabalhador quanto o campo da Reforma Psiquiátrica indicam a necessidade de uma prática reflexiva, com o protagonismo dos trabalhadores e a construção de espaços para problematizaçãodo trabalho, da saúde e das relações de poder/saber presentes no cotidiano dos serviços de atenção em saúde.

Nosso foco esteve nos cruzamentos, atravessamentos e distanciamentos desses dois movimentos que surgem no bojo das discussões em prol de um Sistema Único de Saúde, organizado segundo os princípios da descentralização, atendimento integral e controle social, em um entendimento de que a saúde é resultante de políticas sociais e econômicas, é direito constituinte da cidadania e, portanto, dever do Estado. 
Analisando os principais documentos que sustentam as políticas de Saúde Mental e de Saúde doTrabalhador, i.e., os Relatórios das Conferências Nacionais, percebemos que a Saúde Mental, enquanto tema, é apresentada em ambas as Conferências Nacionais de Saúde do Trabalhador, embora com ênfases distintas e direcionada à discussão do trabalho na iniciativa privada. Já a Saúde doTrabalhador, enquanto objeto nas Conferências Nacionais de Saúde Mental, foi paulatinamente adquirindo importância e passou de uma reivindicação pela inclusão do tema da Saúde Mental do trabalhador na legislação e nas empresas a uma preocupação específica com a Saúde Mental do trabalhador da saúde e com o servidor público. No entanto, a reforma psiquiátrica, pelo menos no início, não teve, como prioridade, a necessidade de uma reflexão sobre o trabalho, ao contrário da Saúde doTrabalhador, que apresenta, como um dos seus principais pilares, justamente o saber do trabalhador.

Acreditamos, seguindo a perspectiva foucaultiana, que as conferências expressam um determinado jogo de verdades, próprio ao jogo científico e político na disputa pela construção de uma nova cidadania brasileira. A reforma sanitária (aqui discutida a partir das políticas públicas relativas à Saúde Mental e à Saúde doTrabalhador) teve, como trunfo, consolidar a saúde como um valor universal, e, ao mesmo tempo, ao instituir o SUS, como um mecanismo subversivo, isso porque, ao definir a saúde como conseqüência das condições de vida da população (na VIII Conferência Nacional de Saúde, em 1986, e, posteriormente, na Constituição Federal de 1988 e na Lei Orgânica da Saúde, de 1990), faz uma denúncia da cristalização da desigualdade social brasileira e coloca a miséria, definitivamente, como uma questão para o Estado, visto que atenta, entre outros, ao direito constitucional à saúde (Fleury, 2005).
Entretanto, repensar a saúde e o processo político de construção do SUS implica problematizar, também, as forças políticas, a relação capital-trabalho, os movimentos sociais e, finalmente, os agentes do Estado (os servidores públicos da saúde). Ao refletirmos genealogicamente sobre as Conferências de Saúde do Trabalhador, percebemos que o sofrimento psíquico custa a ser incorporado como questão, uma vez que está fora do arcabouço institucional-legal que regula(va) a saúde dos e das trabalhadores/as no Brasil. O relatório da primeira Conferência retrata a esfera de luta, que marca o jogo político herdado do novo sindicalismo, contra o poder normalizador da Medicina do Trabalho. Era necessário dar visibilidade, inicialmente, à dor no corpo, para que seu reflexo, tanto na vida como no sutil sofrimento da humilhação no trabalho, pudesse emergir em um segundo momento, ainda hoje incipiente. A disputa em questão, longe de ser vencida, centrava-se em transformar uma relação de cidadania, restrita ao trabalho de carteira assinada, em uma cidadania universalizada pela saúde.

Quanto à Saúde Mental, a violenta desumanização dos manicômios implicou, em um primeiro momento, uma luta contra a lógica positivista que, travestida de diagnóstico, retirava o direito de cidade (à cidadania) daqueles e daquelas cuja razão não cabia na norma única da razão cartesiana. Aqui ainda o trabalhador da saúde era invisível na sua dor. O momento era mais militante que hoje - ali estavam aqueles e aquelas que lutavam pela saúde do louco, em uma disputa acirrada contra o cartel psiquiátrico e os trabalhadores amantes de sua institucionalização. A reforma e a luta antimanicomial precisaram andar, e tomar forma, para que se compreendesse o quanto os manicômios continuavam presentes fora dos muros dos hospitais psiquiátricos.

Certamente, nesta breve análise, só pudemos traçar algumas pistas para a compreensão das disputas pelas formas de legitimação da 
verdade, no campo institucional das políticas públicas de saúde, que culminaram na redação final dos Relatórios das Conferências. É um processo que dá visibilidade a certos elementos e torna outros tantos invisíveis, o que reflete o jogo de forças, sobretudo político, que dá forma à institucionalidade do SUS.

Em que pesem importantes conquistas, os desafios, nesse processo de consolidação de políticas públicas de saúde cidadãs, ainda são imensos, mesmo que mais sutis. Sutis porque se relacionam com uma questão ética central, que diz respeito ao lugar que reservamos ao outro na forma como nos constituímos como sujeitos, ou seja, na forma como nos pensamos como iguais em direitos em nossas relações cotidianas - na relação governoservidor, patrão-empregado, profissional de saúde-usuário, assim como nas relações mais horizontais (servidor-servidor, usuário-usuário, etc).

\begin{tabular}{|r|} 
Tatiana Ramminger \\
Mestre em Psicologia Social e Institucional (UFRGS), doutoranda em Saúde Pública - Escola \\
Nacional de Saúde Pública Sérgio Arouca \\
Fundação Oswaldo Cruz - FIOCRUZ \\
Henrique Caetano Nardi \\
Doutor em Sociologia (UFRGS), professor do Departamento e do Mestrado em \\
Psicologia social e institucional da UFRGS \\
Rua Lima e Silva, 250/104 - RS - 90050-100 \\
Telefone: (51) 3061 3173 \\
E-mail:ramminger@ensp.fiocruz.br, hcnardi@terra.com.br
\end{tabular}

BASAGLIA, F.; GALLIO, G Vocação Terapêutica e Luta de Classes. In: Delgado, J. ALoucura na Sala de Jantar. São Paulo: Resenha, 1991, pp. 27-51.

BRASIL. MINISTÉRIODA SAÚDE. I Conferência Nacional de Saúde do Trabalhador. Relatório Final. Ministério da Saúde, Brasília, 1986.

BRASIL. MINISTÉRIODA SAÚDE. I Conferência Nacional de Saúde Mental. Relatório Final. Ministério da Saúde, Brasília, 1987.

BRASIL. MINISTÉRIODA SAÚDE. II Conferência Nacional de Saúde Mental. Relatório Final. Ministério da Saúde, Brasília, 1993.

BRASIL. MINISTÉRIODA SAÚDE. II Conferência Nacional de Saúde do Trabalhador. Relatório Final. Brasília, 1994.

BRASIL. MINISTÉRIO DA SAÚDE. III Conferência Nacional de Saúde Mental. Relatório Final. Ministério da Saúde, Brasília, 2001.

FLEURY, S. Saúde: o Político, o Social e o Econômico. Aula inaugural da Escola Nacional de Saúde Pública - Fiocruz, 2005. Não publicado.

FOUCAULT, M. Verdade e Poder. In: Machado, R. (org.). Microfísica do Poder. Rio de Janeiro: Ed. Graal, 1999a, pp.1-14.

A Casa dos Loucos. In: Machado, R. (org.) Microfísica do Poder. Rio de Janeiro: Ed. Graal, 1999b, pp. 113-128.
.Genealogia e Poder. In: Machado, R. (org.). Microfísica do Poder. Rio de Janeiro: Ed. Graal, 1999c, pp. 67-177.

NARDI, H. C. Saúde, Trabalho e Discurso Médico. São Leopoldo: Ed. Unisinos, 1999.

PALOMBINI, A. AÉtica nas Micropolíticas de Atenção à Loucura. In: CONSELHO FEDERAL DE PSICOLOGIA (org). Loucura, Ética e Política: Escritos Militantes. São Paulo: Casa do Psicólogo, 2003, pp. 159-163.

RAMMINGER, T. Trabalhadores de Saúde Mental: Reforma Psiquiátrica, Saúde do Trabalhador e Modos de Subjetivação nos Serviços de Saúde Mental. Santa Cruz do Sul: EDUNISC, 2006.

SARACENO, B. Libertando Identidades: da Reabilitação Psicossocial à Cidadania Possível. Rio de Janeiro: IFB/Te Corá, 1999.

VASCONCELOS, E.M. O controle social na reorientação do modelo assistencial em Saúde Mental no Brasil. In: BRASIL, MINISTÉRIO DA SAÚDE (org.). Caderno de Textos da III Conferência Nacional de Saúde Mental. Brasília: Ministério da Saúde, 2001, pp. 42-53.
Referências 